Article

\title{
Textured $\mathrm{Sr}_{2} \mathrm{Sc}_{0.1} \mathrm{Nb}_{0.1} \mathrm{Co}_{1.5} \mathrm{Fe}_{0.3} \mathrm{O}_{6-2 \delta}$ Thin Film Cathodes for IT-SOFCs
}

\author{
Zhaoxin Zhu ${ }^{1,2,3}$, Chuan Zhou ${ }^{4}$, Wei Zhou ${ }^{4, *}$ and Nan Yang ${ }^{1, * \mathbb{D}}$ \\ 1 School of Physical Science and Technology, ShanghaiTech University, 393 Middle Huaxia Road, Pudong, \\ Shanghai 201210, China; zhuzhx@shanghaitech.edu.cn \\ 2 Shanghai Institute of Ceramics, Chinese Academy of Sciences, Shanghai 200050, China \\ 3 University of Chinese Academy of Sciences, Beijing 100049, China \\ 4 Jiangsu National Synergetic Innovation Center for Advanced Materials (SICAM), State Key Laboratory of \\ Materials-Oriented Chemical Engineering, College of Chemical Engineering, Nanjing Tech University, \\ No.5 Xin Mofan Road, Nanjing 210009, China; zhouchuan987654@163.com \\ * Correspondence: yangnan@shanghaitech.edu.cn (N.Y.); zhouwei1982@njtech.edu.cn (W.Z.)
}

Received: 15 January 2019; Accepted: 24 February 2019; Published: 7 March 2019

check for updates

\begin{abstract}
Reducing the operating temperature of solid oxide fuel cells (SOFCs) to intermediate $\left(650-850{ }^{\circ} \mathrm{C}\right)$ or even lower levels $\left(400-650{ }^{\circ} \mathrm{C}\right)$ is an important practical requirement. However, the main obstacle to lowering the operating temperature is the poor oxygen reduction reaction (ORR) activity on the cathode side and, therefore, it is essential to explore cathode materials with good ORR activity in these temperature ranges. In this work, we investigated the possibility of using $\mathrm{Sr}_{2} \mathrm{Sc}_{0.1} \mathrm{Nb}_{0.1} \mathrm{Co}_{1.5} \mathrm{Fe}_{0.3} \mathrm{O}_{6-2 \delta}$ (SSNCF) as a suitable intermediate temperature cathode material. SSNCF thin films with different orientations were prepared using the pulsed laser deposition technique, and the relationship of the surface chemical states and ORR activity was discussed in terms of crystallographic orientation. The results showed that the SSNCF/YSZ grown along the [110] direction exhibited superior ORR activity compared to the SSNCF/SDC/YSZ thin film electrode grown along the [100] direction. This was explained by the variation in the Sr-surface enrichment and cobalt ion oxidation state using $X$-ray photoemission spectroscopy.
\end{abstract}

Keywords: SOFCs; mixed ionic electronic conductor; ORR; thin films; surface chemistry

\section{Introduction}

Solid oxide fuel cells (SOFCs) are a type of device that converts the chemical energy from fuel directly into electrical energy without the need for combustion. SOFCs have been continuously investigated for their simple structure, high energy conversion efficiency, fuel flexibility, and zero exhaust gas emission (i.e., $\left.\mathrm{SO}_{2}, \mathrm{NO}\right)$. However, the high operating temperature $\left(>850^{\circ} \mathrm{C}\right)$ results in high maintenance costs and material compatibility issues. Over the past decade, significant progress has been made to bring the operating temperature down to the intermediate $\left(650-850{ }^{\circ} \mathrm{C}\right)$ and even lower ranges $\left(400-650{ }^{\circ} \mathrm{C}\right)$ [1]. When the temperature is below $650{ }^{\circ} \mathrm{C}$, the polarization resistance (Rp) of the oxygen reduction reaction (ORR) $\left(\mathrm{O}_{2}+4 \mathrm{e}^{-} \rightarrow 2 \mathrm{O}^{2-}\right)$ on the cathode increases significantly, due to the sluggish reaction kinetics that occur at lower temperatures [2,3]. Continuous improvements to cathode materials have been made, specifically, mixed ionic and electronic conducting (MIEC) oxides with a perovskite structure, such as $\mathrm{La}_{1-x} \mathrm{Sr}_{x} \mathrm{CoO}_{3-\delta}$ and $\mathrm{Ba}_{1-x} \mathrm{Sr}_{\mathrm{x}} \mathrm{Co}_{1-y} \mathrm{Fe}_{\mathrm{y}} \mathrm{O}_{3-\delta}$, have been widely proposed as cathode materials for SOFCs [4]. MIEC oxides not only provide electrons for the oxygen reduction reaction, but they also facilitate the transfer of oxygen ions to the electrolyte. As a result, the ORR is no longer limited to the three-phase-boundary of the cathode, electrolyte, and gas molecules, as the active sites can now be enlarged to the whole cathode surface [5]. 
$\mathrm{SrCoO}_{3-\delta}$-based solid solutions with high oxygen ion conductivity and good ORR activity related to the $\mathrm{Co}^{3+} / \mathrm{Co}^{4+}$ redox couple have also attracted wide attention for improving the cathode performance at low temperatures [6,7]. Chemical doping strategies were adopted to further tailor the $\mathrm{SrCoO}_{3-\delta}$ based cathode performances. For example, by substituting Co with donor dopants, such as $\mathrm{Sc}$ and $\mathrm{Nb}$ ions, an enhancement in the electronic conductivity can be achieved. In addition, doped $\mathrm{SrCoO}_{3-\delta}$ based cathodes possess a better phase stability under thermal cycling and long-term working conditions compared to the parental phase $[8,9]$. Furthermore, replacing Co ions with a small amount of Fe ions can improve the overall cell performance. In addition to the enhanced ORR activity, Fe-doped $\mathrm{SrCoO}_{3-\delta}$-based cathodes demonstrate a lower thermal expansion coefficient and better $\mathrm{CO}_{2}$ tolerance. According to related work, these properties could be also related to the oxygen non-stoichiometric effect $[10,11]$. Recently, Chuan Zhou et al. prepared a novel kind of doped $\mathrm{SrCoO}_{3-\delta}$ cathode, i.e., $\mathrm{Sr}_{2} \mathrm{Sc}_{0.1} \mathrm{Nb}_{0.1} \mathrm{Co}_{1.5} \mathrm{Fe}_{0.3} \mathrm{O}_{6-\delta}$ (SSNCF). By simultaneously doping $\mathrm{Sc}$, $\mathrm{Nb}$, and $\mathrm{Fe}$, both the electronic and ionic conductivity could be improved, making SSNCF a potential candidate for intermediate temperature application [12]. Although $\mathrm{Sc}-, \mathrm{Nb}-$, and $\mathrm{Fe}$-doped $\mathrm{SrCoO}_{3-\delta}$ cathode materials were intensively investigated, the most reported works were performed using samples comprising of ceramics pellets and thick polycrystalline films [13,14]. However, owing to the complicated effects caused by grain boundaries, defect densities, and crystal grain sizes, their intrinsic activities were not completely explored. Furthermore, some properties related to the surface states, such as the oxygen adsorption and incorporation, as well as surface degradation are believed to be anisotropic. Therefore, precisely controlling the growth of single crystal thin film could be beneficial in understanding the complex function coupling between the ORR and the crystallographic orientation dependent surface states.

With the development of epitaxial film technology, thin film cathodes have been proposed as a tool to investigate intrinsic electrochemical activities [15]. Thin film cathodes with well-defined crystallographic orientation, low surface roughness, and a dense microstructure offer a comparable platform to further understand the ORR process [16,17]. Amongst all the possible thin film fabrication technologies, pulsed laser deposition (PLD) has been generally applied to prepare high quality complex oxide films due to its flexibility $[18,19]$. It has been previously used to prepare SOFC cathodes in both the fundamental studies and in practical applications [20].

In this paper, with the aim of shedding more light on the complex relationship between the ORR and the crystallographic orientation dependent surface states of SSNCF, we deposited using PLD, approximately $60 \mathrm{~nm}$ thick SSNCF oriented thin film electrodes on (100) single crystalline $8 \mathrm{~mol} \% \mathrm{Y}_{2} \mathrm{O}_{3}$-stabilized $\mathrm{ZrO}_{2}$ (YSZ) substrates. YSZ substrates with a cubic structure and $\mathrm{a}=5.14 \AA$ were chosen due to their suitable lattice constant, good ionic conductivity, and negligible electronic conductivity, thereby allowing reliable transport measurements. The half in-plane lattice parameter was $3.63 \AA$ along the [110] direction of the YSZ substrate, and considering the lattice parameter of SSNCF (cubic structure a $=3.92 \AA$ ), the in-plane mismatch was about $7 \%$. The poor lattice match both in terms of crystal structure and lattice parameter could lead to a [110] direction growth, which has previously been reported for the deposition of $\mathrm{La}_{0.8} \mathrm{Sr}_{0.2} \mathrm{CoO}_{3-\delta}$ and $\mathrm{LaNiO}_{3}$ on YSZ substrates $[19,21]$. To reorient the SSNCF growth direction; we grew the SSNCF thin film on the $10 \mathrm{~nm}$ thick $20 \mathrm{~mol} \% \mathrm{Sm}$ doped $\mathrm{CeO}_{2}$ (SDC, cubic structure $\mathrm{a}=5.4 \AA$ ) buffered $\mathrm{YSZ}$ substrate. By introducing the SDC buffer layer, the in-plane mismatch between the SDC and SSNCF was reduced to about $3 \%$. A better in-plane lattice parameter match could result in growth in the [001] direction.

\section{Materials and Methods}

\subsection{Powder and Target Preparation}

SSNCF powders were prepared via a combined EDTA-citrate complexing method. $\operatorname{Sr}\left(\mathrm{NO}_{3}\right)_{2}$, $\mathrm{Sc}\left(\mathrm{NO}_{3}\right)_{3}, \mathrm{Co}\left(\mathrm{NO}_{3}\right)_{2} \cdot 6 \mathrm{H}_{2} \mathrm{O}, \mathrm{Fe}\left(\mathrm{NO}_{3}\right)_{3}$, and $\mathrm{NbC}_{2} \mathrm{O}_{4}$ were dissolved in water at the desired molar ratio. Next, the solution was mixed with EDTA- $\mathrm{NH}_{3}$ and citric acid to obtain a solution with a $\mathrm{pH}$ value 
adjusted to 7 . After further evaporation at $80^{\circ} \mathrm{C}$ for $5 \mathrm{~h}$, the precursor was first calcined at $250{ }^{\circ} \mathrm{C}$ for $5 \mathrm{~h}$, and then at $900^{\circ} \mathrm{C}$ for $5 \mathrm{~h}$ in air to obtain SSNCF powder. The powders were collected and made into pellets under pressure of $14 \mathrm{MPa}$ for the targets. Finally, round-shaped pellets of a $12 \mathrm{~mm}$ diameter size were sintered at $1200{ }^{\circ} \mathrm{C}$ for $5 \mathrm{~h}$ in air at a heating and cooling rate of $6{ }^{\circ} \mathrm{C} / \mathrm{min}$.

\subsection{Thin Film Deposition}

SSNCF films were grown by pulsed laser deposition (PLD) using the nanoPLD instrument from PVD Inc. (Wilmington, MA, USA). The KrF excimer pulsed laser source (COMPEX PRO $110 \mathrm{~F}$, Cooherent LaserSystems GmbH \& Co. KG., Göttingen, Germany) was operated at $10 \mathrm{~Hz}$, with an energy density of $2 \mathrm{~J} / \mathrm{cm}^{2}$; and the substrate temperatures were kept at $600{ }^{\circ} \mathrm{C}, 700{ }^{\circ} \mathrm{C}$, and $800{ }^{\circ} \mathrm{C}$ during the thin film growth, respectively. The oxygen partial pressure was $50 \mathrm{mTorr}$, with a constant oxygen flux of $50 \mathrm{sccm}$. The distance from target to substrate was kept at $60 \mathrm{~mm}$. For thin films of different orientations, two sets of the samples were prepared: (i) Fully covered films were prepared for the structural, morphological and electrical transport measuremnts. (ii) For the measurements of electrochemical performances, symmetrical SSNCF film electrodes were fabricated on the substrate.

\subsection{X-ray Diffraction}

The crystallographic quality and crystal structure of the SSNCF thin films were characterized by X-Ray diffraction (XRD) in the Bragg-Brentano geometry using a high resolution X-ray diffraction (HRXRD, Panalytical, Almelo, Netherlands) instrument. The X-ray source was $\mathrm{Cu} K \alpha(\lambda=1.5406 \AA)$. The $\theta-2 \theta$ measurements in the $2 \theta$ range of $20-60^{\circ}$ were performed at $0.02^{\circ}$ steps and an acquisition time of $0.2 \mathrm{~s}$ at each step, as well as characterizing the rocking curve in the range of $\pm 1.5^{\circ}$ near the corresponding characteristic peak. The working voltage and current of this instrument were set at $45 \mathrm{kV}$ and $40 \mathrm{~mA}$, respectively.

\subsection{Atomic Force Microscopy Characterization}

The surface morphology of the thin films was characterized by atomic force microscopy (AFM). All topographic images were acquired under dry conditions in the tapping mode using silicon cantilevers at about $300 \mathrm{kHz}$ through a Dimension Icon AFM with a Nanoscope V controller (Digital Instruments, Goleta, CA, USA).

\subsection{Electrochemical Impedance Spectroscopy Measurement}

The electrochemical impedance spectroscopy (EIS) measurements were accomplished by an electrochemical workstation (Bio-Logic, SP-300, Seyssinet-Pariset, France). Symmetrical SSNCF film electrodes with $2 \mathrm{~mm} \times 5 \mathrm{~mm}$ dimensions were grown by PLD using a properly designed steel mask. The separation distance was $1 \mathrm{~mm}$. The current was collected using Au wires bonded with Au paste on the two thin film electrodes. Measurements were performed in dry air with the flow rate of $100 \mathrm{sccm}$, and in the cooling ramp from 650 to $400{ }^{\circ} \mathrm{C}$, with a temperature interval of $50{ }^{\circ} \mathrm{C}$. Before the test, the temperature was first raised to $650^{\circ} \mathrm{C}$ in $60 \mathrm{~min}$, and then held at that level for one hour. All the samples were tested in the middle of the thermostatic section. Thereafter, a $100 \mathrm{mV}$ AC voltage with a frequency range from $7 \mathrm{MHz}$ to $10 \mathrm{MHz}$ was applied.

\subsection{Conductivity Measurement}

The DC conductivity measurements (KEITHLEY, 2450 Source Meter, Cleveland, OH, USA) were performed via a Van-Der Pauw configuration. Four gold electrodes were painted on the edge of the sample with an average separation of $5 \mathrm{~mm}$. The measurements were carried out in the temperature range of $400-650{ }^{\circ} \mathrm{C}$ during the heating ramp, and then repeated a few times to check the reliability of the results. 


\subsection{X-ray Photoelectron Spectroscopy}

The X-ray photoelectron spectroscopy (XPS) measurements were established using the Thermo Fisher ESCALAB 250XI (Fisher Scientific, Hampton, NH, USA). The ray source used was Al K $\alpha$ radiation, $1486.74 \mathrm{eV}$ energy which corresponded to an electron inelastic mean free path for the SSNCF samples of about $2.4 \mathrm{~nm}$. For the single element analysis, the full spectrum of pass energy was $50 \mathrm{eV}$ and $30 \mathrm{eV}$ for the valence band spectra. The emission angle was $30^{\circ}$.

\section{Results and Discussion}

\subsection{Thin Film Growth Optimization}

Using PLD, $60 \mathrm{~nm}$ thick SSNCF thin films were deposited on (100)-oriented yttrium-stabilized zirconia (YSZ) substrates. The film thickness of the film grown at $800{ }^{\circ} \mathrm{C}$ was corrected by field emission scanning electron microscopy, and the thickness correction for the films grown at lower temperatures was performed using X-ray reflectivity measurements. (In Supplementary Materials Section S1 for field emission scanning electron microscopy images and for the $\mathrm{X}$-ray reflectivity measurements). The growth temperature of the SSNCF thin films was optimized at $600^{\circ} \mathrm{C}, 700{ }^{\circ} \mathrm{C}$, and $800^{\circ} \mathrm{C}$. The XRD patterns are shown in Figure 1a. The sample prepared at $600{ }^{\circ} \mathrm{C}$ showed no characteristic peak of the SSNCF thin film, and indicated a poor crystallinity of the samples. For the films grown at $700{ }^{\circ} \mathrm{C}$ and $800{ }^{\circ} \mathrm{C}$, both films showed a diffraction peak near $32^{\circ}$, which could be assigned to the (110) reflection of the SSNCF. The lattice parameter of the thin films was calculated to be $3.93 \AA$, similar to its bulk value [11,12]. We further compare the surface quality of the SSNCF thin films prepared at different temperatures by atomic force microscopy (AFM). From the AFM images shown in the inset of Figure 1a, the film deposited at $600{ }^{\circ} \mathrm{C}$ shows agglomerated large grains with the highest surface roughness. This may have been due to the slow surface nucleation process and growth kinetics at lower temperatures [10]. The surface roughness decreased from $2.82 \mathrm{~nm}$ at a growth temperature of $600{ }^{\circ} \mathrm{C}$ to $0.87 \mathrm{~nm}$ at a temperature of $800{ }^{\circ} \mathrm{C}$.

(a)

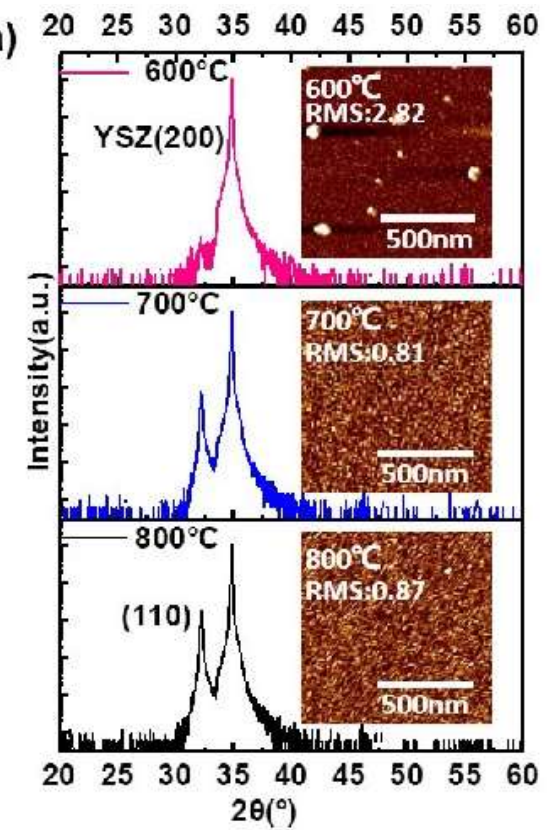

(b)

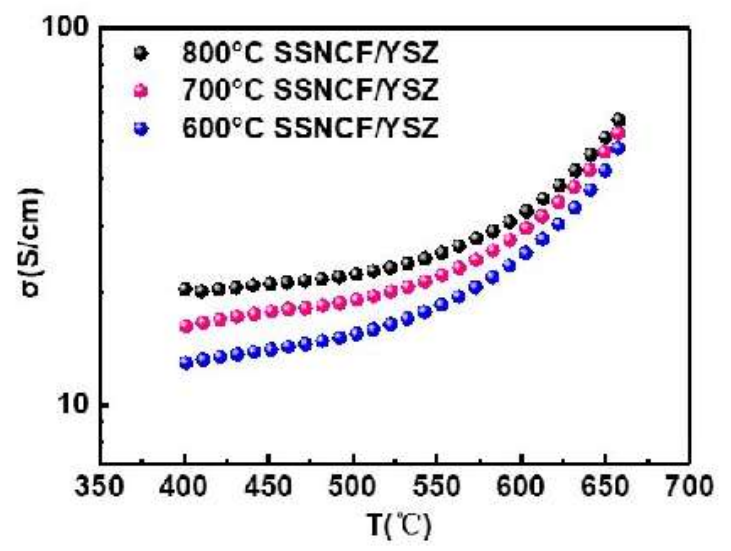

Figure 1. (a) X-ray diffraction spectra and atomic force microscopy (AFM) images of the SSNCF thin films grown at different temperatures. (b) Temperature-dependent electronic conductivities of the SSNCF thin films.

The results of the temperature dependent electronic conductivity measurements are shown in Figure $1 \mathrm{~b}$. The measurements were performed at a temperature range of $650{ }^{\circ} \mathrm{C}$ to $400{ }^{\circ} \mathrm{C}$ in air. 
The overall electronic conductivity increased as a function of the temperature, indicating a thermal activated semiconducting hopping behavior [22]. The conductivities improved with the increasing thin film deposition temperature over the whole temperature range. For example, at $650{ }^{\circ} \mathrm{C}$, the electronic conductivity increased from $48 \mathrm{~S} / \mathrm{cm}$ for the SSNCF film grown at $600{ }^{\circ} \mathrm{C}$ to $57 \mathrm{~S} / \mathrm{cm}$ deposited at $800{ }^{\circ} \mathrm{C}$. Based on the results of the crystal structural, morphological, and electronic transport characterization, the thin film grown at $800{ }^{\circ} \mathrm{C}$ exhibited good crystallographic quality, low surface roughness, and acceptable electronic conductivity. Therefore, we choose $800{ }^{\circ} \mathrm{C}$ as the deposition temperature to fabricate SSNCF thin film electrodes for further electrochemical characterization.

\subsection{Structure Reorientation with a Buffer Layer}

To influence the growth orientation of SSNCF, a $10 \mathrm{~nm}$ thick SDC buffer layer was introduced onto the (100)-oriented YSZ substrate before fabricating the SSNCF thin film. The better in plane lattice parameter match led to the growth of the SSNCF thin film in the [100] direction. The SDC is an oxygen-ion conductor with similar thermal expansion coefficient and ionic conductivity to the YSZ [23,24]. The ultra-thin SDC buffer layer can reorient the SSNCF growth direction without significantly modifying the oxygen ion conductivity of the YSZ single crystal substrate. The epitaxial relationships are demonstrated in the Figure 2a. Typical X-Ray scans of the SSNCF/YSZ sample and the SSNCF/SDC/YSZ sample are shown in Figure $2 \mathrm{~b}$. Only the (100) reflections from SSNCF were visible in the SSNCF/SDC/YSZ, suggesting that the film was highly textured along the [100] direction. In the case of the SSNCF/YSZ, the presence of only the (110) reflection demonstrated the SSNCF thin film growing along the [110] direction. Such observation proofs that the SDC buffer layer could be used to adjust the film growth, allowing us to directly investigate the growth orientation dependent SSNCF's ORR activity. To rule out the possible overlap presented by the SDC buffer layer and SSNCF, we carefully compared the XRD pattern of the SDC/YSZ and SSNCF/SDC/YSZ, as seen in Supplementary Materials Section S4. Only the (100) peaks of the SDC were observed, indicating a good crystallinity of SDC buffer layer. More importantly, the SDC diffraction peaks were almost identical without any peak width broadening and intensity decrement after the deposition of the SSNCF layer, which was extremely help for us in ruling out the presence of (110)-oriented grains of the SSNCF layer. We calculated the lattice parameters of both samples using Bragg's equation. The lattice parameter of the SSNCF/YSZ thin film was $3.93 \AA$, while the lattice parameter of the SSNCF/SDC/YSZ was $3.95 \AA$. The films crystallographic quality was examined by Rocking curve measurements. The SSNCF grown directly on the YSZ demonstrated a smaller half width at half maximum than on the SDC buffered YSZ, as shown in Supplementary Materials Section S2. Such results indicated that a better crystallographic quality was achieved for the SSNCF/YSZ.

\subsection{ORR Activity}

To study the oxygen reduction reaction (ORR) performance of the cathode, the electrochemical impedance spectra (EIS) measurements were performed at a range of $400^{\circ} \mathrm{C}$ to $650^{\circ} \mathrm{C}$ in air. The sample setup is shown in Figure 3a. Two strips of SSNCF thin film electrodes were deposited on YSZ and SDC buffered YSZ substrates, respectively. The Nyquist plots of the SSNCF/YSZ and SSNCF/SDC/YSZ thin film electrodes obtained from the EIS measurement at $650^{\circ} \mathrm{C}$ are shown in Figure $3 \mathrm{~b}$. Both Nyquist plots showed two semicircles. The impedance spectrum was further divided into a high frequency (HF) semicircle and a low frequency (LF) one, as indicated in Figure 3b. The HF semicircle was related to the limited oxygen ion conductivity of the YSZ and SDC buffered YSZ substrates. As expected, the $10 \mathrm{~nm}$ thick SDC buffer layer did not introduce any observable variation in the Nyquist plot. On the other hand, the LF semicircle was linked to the ORR polarization process. 
(a)

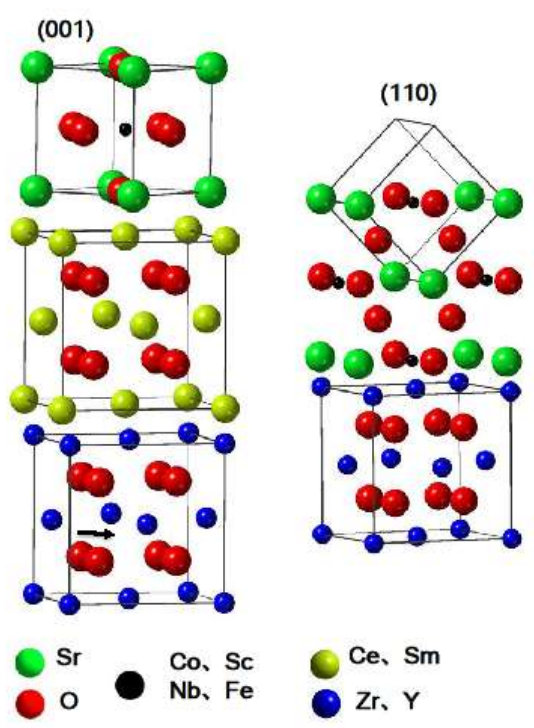

(b)

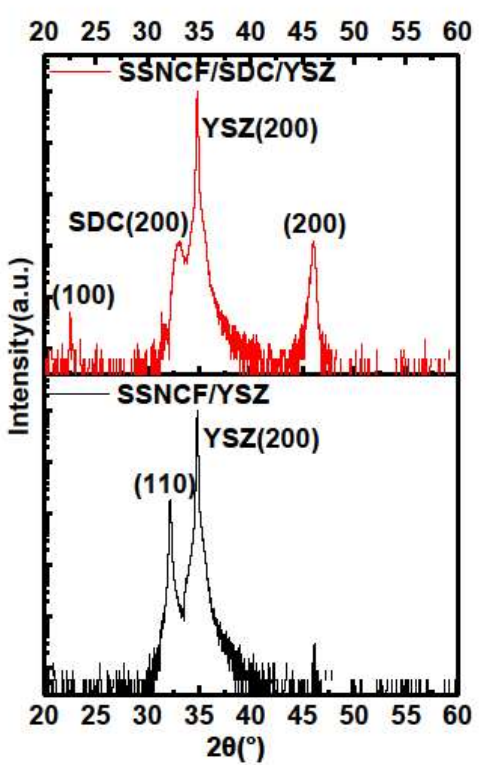

Figure 2. (a) Schematic sketch of the correlation between the SSNCF, SDC, and YSZ of different oriented SSNCF thin films. (b) X-ray diffraction spectra of the SSNCF thin films on the substrate with or without the SDC buffer layer.
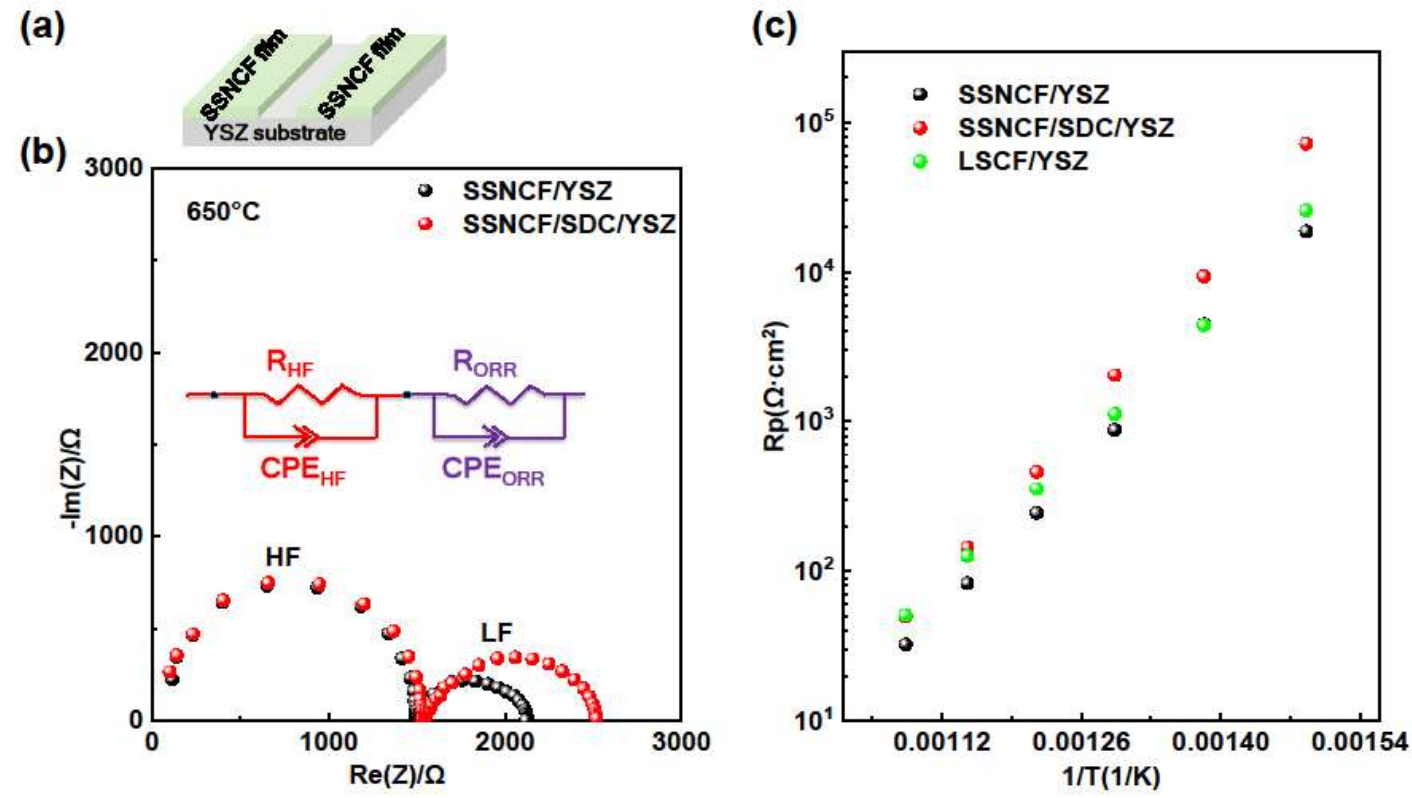

Figure 3. (a) Sketch of sample the SSNCF thin film on the YSZ substrate (b) Nyquist plots of the SSNCF thin films measured at $650{ }^{\circ} \mathrm{C}$ in air, with the equivalent circuit inset. (c) The Arrhenius type Rp plots of the SSNCF thin films and reference LSCF thin film.

The plots were fitted by two RC equivalent circuits in series, which is the inset of Figure $3 b$. The fitting details could be found in Supplementary Materials Section S3. The polarization resistance (Rp) estimated from the LF part varied with the thin films' crystallographic orientation. At $650{ }^{\circ} \mathrm{C}$, the Rp value of the SSNCF/YSZ and SSNCF/SDC/YSZ were $30.9 \Omega \cdot \mathrm{cm}^{2}$ and $45.6 \Omega \cdot \mathrm{cm}^{2}$, respectively. The SSNCF thin film electrodes grown along the [110] had lower $R_{p}$, suggesting a superior ORR activity compared to the sample grown along the [100] direction.

Figure $3 c$ gives the Arrhenius type $R_{p}$ plots of the SSNCF/YSZ and SSNCF/SDC/YSZ thin film electrodes. The $R_{p}$ of the SSNCF/YSZ was smaller than the SSNCF/SDC/YSZ in the whole temperature range, which could either be due to a better crystalline quality and/or different surface 
chemical states. The activation energy $\left(E_{a}\right)$ obtained from the $R_{p}$ plots was $1.45 \mathrm{eV}$ for the SSNCF/YSZ and $1.62 \mathrm{eV}$ for the SSNCF/SDC/YSZ sample. The fitting equation was $R_{p}=R_{p}^{0} \exp \left(-\frac{E a}{K_{B} T}\right)$ as described by $\mathrm{H}$. Tuller et al. [25]. Such values are typical for MIEC electrodes, as previously reported for $\mathrm{La}_{1-\mathrm{x}} \mathrm{Sr}_{\mathrm{x}} \mathrm{CoO}_{3-\delta}$ and $\mathrm{Ba}_{1-\mathrm{x}} \mathrm{Sr}_{\mathrm{x}} \mathrm{Co}_{1-\mathrm{y}} \mathrm{Fe}_{\mathrm{y}} \mathrm{O}_{3-\delta}$ [4]. The ORR activity of the SSNCF thin film electrodes were compared with the state-of-the-art $\mathrm{La}_{0.6} \mathrm{Sr}_{0.4} \mathrm{Co}_{0.8} \mathrm{Fe}_{0.2} \mathrm{O}_{3-\delta}$ (LSCF) thin film electrodes with the same thickness on the (100) oriented YSZ substrate. Both SSNCF thin film electrodes showed similar Rp compared to the LSCF, suggesting that the SSNCF thin film electrodes may be considered as a potential cathode material for IT-SOFCs.

The rate-determining step of the ORR process was investigated by the $\mathrm{pO}_{2}$ dependent EIS measurements at $650{ }^{\circ} \mathrm{C}$. The dependence of the Rp on the partial pressure of oxygen generally demonstrated the following $\mathrm{R}_{\mathrm{P}} \propto \mathrm{P}_{\mathrm{O}_{2}}^{-m}$ behavior. The exponential factor $m$ can be used to describe the kinetic rate-determining step during the ORR process [25]. When $m$ equals to 0.25 , the reaction kinetics are controlled by oxygen dissociation, and if $m$ equals to 0.5 , the charge transfer process occurring at the air-electrode or electrode-electrode interface is the most crucial step for the reaction kinetics [10]. The $\mathrm{pO}_{2}$-dependent EIS results can be found in Figure 4. Both the SSNCF/YSZ and SSNCF/SDC/YSZ samples demonstrate larger Rp values at a lower partial pressure of oxygen, confirming their cathodic nature. In addition, the $m$ values obtained from fitting the experimental data with the above equation were 0.393 for the SSNCF/YSZ and 0.303 for the SSNCF/SDC/YSZ. Such values suggested that both of them may have included both the oxygen adsorption/dissociation and the charge transport contributions. The increment of $\mathrm{m}$ could indicate the rate-determining step shifts from oxygen adsorption/dissociation for the SSNCF/YSZ thin film and to charge transport for the SSNCF/SDC/YSZ.

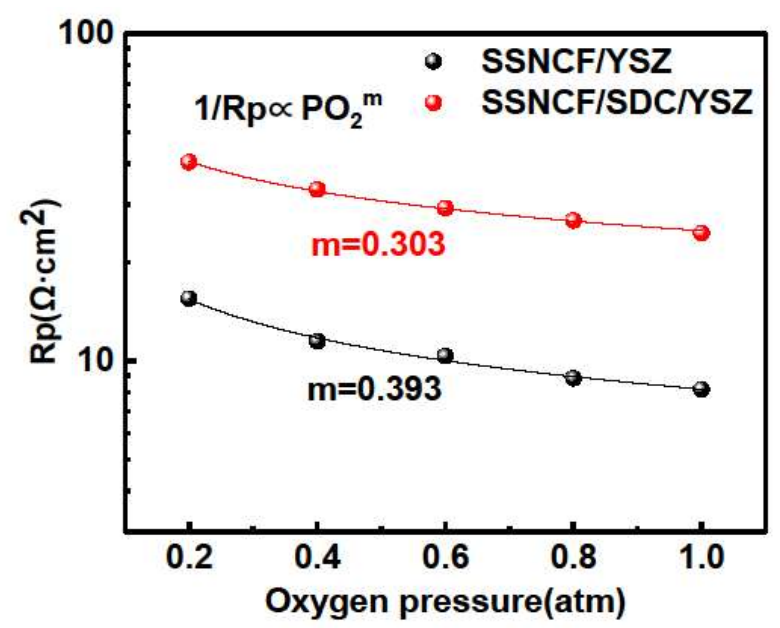

Figure 4. The pO2 dependent Rp of the SSNCF thin film electrodes grown on the YSZ- and SDC-buffered YSZ substrates at $650{ }^{\circ} \mathrm{C}$ with partial pressure of oxygen in the range 1-0.1 atm.

\subsection{Surface Sensitive X-Ray Photoelectron Spectroscopy}

To further understand the significant crystallographic orientation dependent ORR activity and to make connections to their surface states. Surface-sensitive X-Ray photoelectron spectroscopy (XPS) was applied to the SSNCF/YSZ and SSNCF/SDC/YSZ thin films. The Co valence state and surface chemistry were determined by measuring the $\mathrm{Co}, \mathrm{O}$, and $\mathrm{Sr}$ core levels. The dopants showed relatively poor signal to noise ratio due to their limited spatial resolution. Therefore, the core level spectra of the dopants were not conducted with the multicomponent fitting analysis.

Figure 5 shows the XPS results and fitting information for the three elements $\mathrm{Sr}, \mathrm{O}$, and Co The report from Crumlin et al. has linked ORR activity to the surface Sr content [26]. The surface Sr enrichment, typically in the form of Sr based oxide, carbonates, and hydroxide, has been considered as one of the main reasons for surface deactivation of the ORR. As observed in the Figure $5 a, b$ the $\mathrm{Sr}$ 
3d and O 1s spectra had different shapes for the SSNCF/YSZ and SSNCF/SDC/YSZ samples. Based on our previous work on $\mathrm{La}_{1-x} \mathrm{Sr}_{x} \mathrm{CoO}_{3-\delta}$ thin films, the $\mathrm{Sr} 3 \mathrm{~d}$ can be deconvoluted into "surface" and "lattice" components [15]. Each component contains a doublet of spin orbit components with a splitting energy of $1.4 \mathrm{eV}$ [27]. The low energy doublet $\left(\mathrm{BE}_{5 / 2}=132.4 \mathrm{eV}\right)$ is attributed to the lattice component in the SSNCF, named as "lattice". The high energy doublet $\left(\mathrm{BE}_{5 / 2}=133.8 \mathrm{eV}\right)$ was assigned to the Sr surface species, named as "surface". The O 1s spectrum could be deconvoluted into the corresponding "surface" and "lattice" components as well. The low energy "lattice" component at $529.1 \mathrm{eV}$ was related to the oxygen in the SSNCF lattice, and the high energy "surface" at $531.4 \mathrm{eV}$ could be assigned to the Sr enriched surface species [28].

A noticeable decrease of "surface" and "lattice" ratio of Sr 3d spectra to 0.74 for the SSNCF/ SDC/YSZ and 0.71 for the SSNCF/YSZ thin film could be obtained. A similar trend was observed in O 1s spectra, that is the "surface" and "lattice" ratio decreased from 2.44 for the SSNCF/SDC/YSZ to 2.08 for the SSNCF/YSZ sample. Such results were in agreement with the orientation dependent ORR activity of the SSNCF thin film electrodes. The stronger Sr enrichment for the SSNCF/SDC/YSZ may lead to a reduction in the ORR activity. The stronger $\mathrm{Sr}$ enrichment could be due to the worsening crystallographic quality of the SSNCF/SDC/YSZ compared to the SSNCF/YSZ, as shown in Supplementary Materials Section S2. The possible crystal defects could lead to a more facile Sr transport during growth and thus, a greater Sr enrichment at the surface.
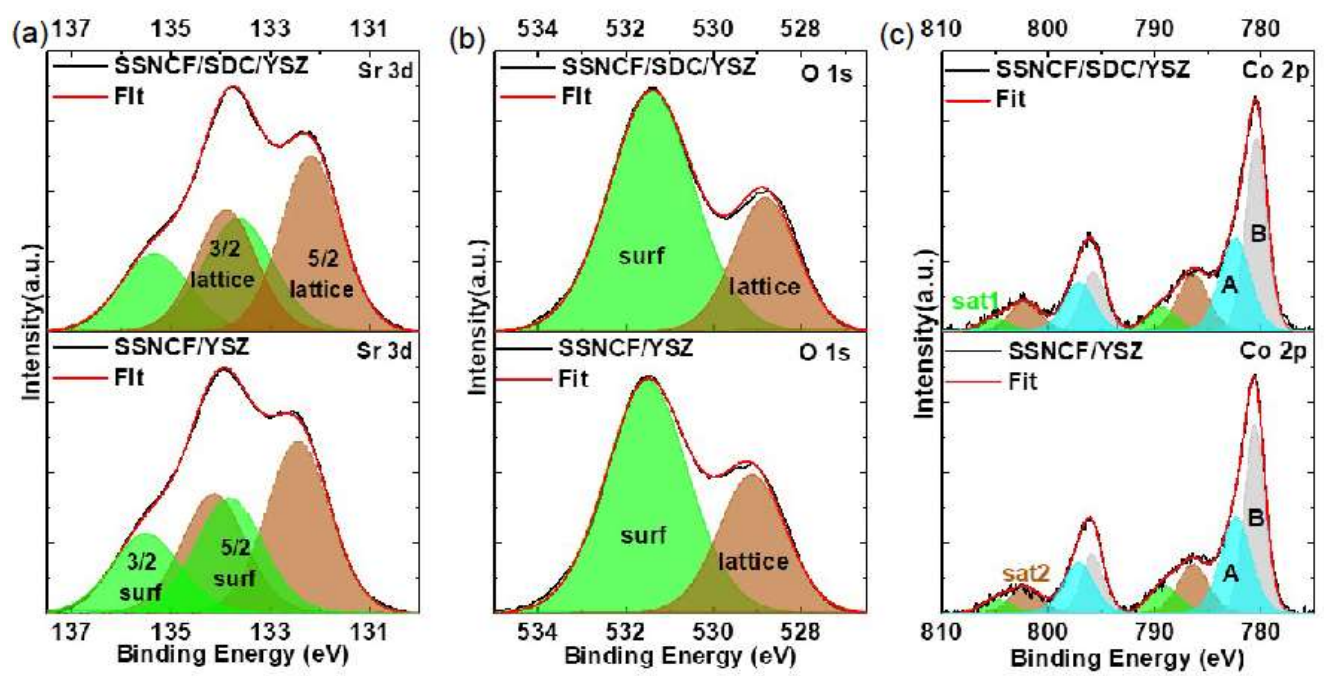

Figure 5. X-ray photoelectron spectroscopy (XPS) and fitted data of Sr, O and Co core level spectra.

The spectra of Co $2 p$ for the SSNCF/SDC/YSZ and SSNCF/YSZ thin films are shown in Figure 5c, from which the $2 p_{1 / 2}$ and $2 p_{3 / 2}$ spin-orbit doublet can be found. Owing to the presence of the screening effect, the exact determination of the cobalt valence state from the main core level peaks was quite challenging. However, it is well accepted the $\mathrm{Co} 2 \mathrm{p}_{3 / 2}$ binding energy can be used to determine the cobalt ion valence state: the binding energy increases from cobalt (II) to cobalt (III). Such a shift is due to the increase in the effective charge of the cobalt metallic center [29]. In Figure $5 c$ it was found that the $\mathrm{Co} 2 p_{3 / 2}$ binding energy increased from $780.5 \mathrm{eV}$ for the SSNCF/SDC/YSZ to $780.6 \mathrm{eV}$ for the SSNCF/YSZ. This observation indicated that the SSNCF thin film grown along the [110] direction could possess a higher cobalt ion oxidation state, which is believed to be essential for enhancing the ORR activity [30,31]. It should be noted that the spectra contained "shake-up" satellites (Sat 1 and Sat 2), as shown in Figure 5c. Sat 1, which was $8 \mathrm{eV}$ higher than the main component at $797 \mathrm{eV}$, could be assigned to the charge transfer from the $\mathrm{O} 2 \mathrm{p}$ to $\mathrm{Co}^{3+}$ and $\mathrm{Co}^{4+} 3 \mathrm{~d}$ orbitals. The Sat 2 with a peak position $6 \mathrm{eV}$ higher than the main component was generally attributed to cobalt (II) with high-spin state. Therefore, the cobalt ion oxidation state variation could also be evaluated from the ratio of Sat 1 to Sat 2 . The larger the ratio is, the higher the cobalt ion oxidation state. This observation was in 
agreement with [31] that a stronger surface segregation could lead to a reduction in the oxidation state of cobalt ion due to a reduced oxygen content. The ratio increased from 0.43 for SSNCF/SDC/YSZ to 0.55 for SSNCF/YSZ, supporting the observation obtained from the Co $2 \mathrm{p}_{3 / 2}$ main component. That is, the (110) oriented SSNCF thin film electrodes cobalt ion oxidation state is higher than (100) oriented SSNCF thin film electrodes. From these surface sensitive XPS measurements, lower Sr enriched surface species and higher cobalt ion oxidation states observed for the SSNCF/YSZ were helpful in explaining the improved ORR activities.

\section{Conclusions}

In this work, $60 \mathrm{~nm}$ thick SSNCF thin films with good crystallinity and flat surface roughness were prepared using PLD at $800^{\circ} \mathrm{C}$. The thin film on the YSZ substrate and on the SDC/YSZ substrate had different growing directions, being the [110] and [100], respectively. From the current investigation, the SDC buffer layer proved to be valid for adjusting the growth direction of the SSNCF thin film. The ORR activities of the SSNCF thin film electrodes with different crystallographic orientations were compared using EIS measurements in air. The film grown along the [110] direction demonstrated lower polarization resistances and smaller activation energy than the film grown along [100] direction, indicating a better ORR activity. A comparison with the state-of-the-art LSCF thin film electrode suggested that the SSNCF film could be a good potential candidate as a cathode working in the intermediate temperature range. The crystallographic orientation dependence of the ORR activities was linked to surface chemistry through XPS characterization. It was found that lower Sr-enrichment and higher cobalt-ion oxidation states were beneficial for the ORR process. This investigation of the SSNCF thin films with different crystallographic orientation can be helpful in taking a step forward in the optimization of thin films' electrochemical activity through tunable crystallographic orientation.

Supplementary Materials: The following are available online at http:/ /www.mdpi.com/1996-1944/12/5/777/s1, Figure S1: FE-SEM micrograph (cross-section) of LSCO/YSZ film, Figure S2: XRR patterns of thin films prepared at 700 and $600{ }^{\circ} \mathrm{C}$, Table S1: Roughness and projected difference on the surface area for the SSNCF films grown on the YSZ and SDC/YSZ substrates with different temperatures, Figure S3: Atomic force microscopy of SSNCF/YSZ and SSNCF/SDC/YSZ, Figure S4: Rocking curves of SSNCF thin films with different orientation, Figure S5: (a) Nyquist plots of the LSCF and SSNCF samples in air at $650{ }^{\circ} \mathrm{C}$ with the equivalent circuit used to fit data. (b) The temperature dependent polarization resistance (Rp) in a logarithmic scale of different thin films in dry air from $400{ }^{\circ} \mathrm{C}$ to $650{ }^{\circ} \mathrm{C}$, Figure S6: Nyquist plots of the before and after regulation SSNCF film electrodes under different temperatures, Table S2: Fitting results of the SSNCF/YSZ electrode, Figure S7: Nyquist plots of the SSNCF and LSCF film electrodes under different temperatures, Table S3: Fitting results of the SSNCF/SDC/YSZ electrode. Figure S8: XRD pattern comparison of SDC/YSZ and SSNCF/SDC/YSZ.

Author Contributions: N.Y., W.Z., and Z.-X.Z. designed this project. C.Z. synthesized the material in powder form and helped in preparation of the PLD target. Z.-X.Z. performed the experiments and analyzed the data. Z.-X.Z. and N.Y. prepared the first draft. All authors participated the discussion and the revision of this manuscript.

Funding: W.Z. acknowledges the financially support received from the National Natural Science Foundation of China under (no. 21576135), Jiangsu Natural Science Foundation for Distinguished Young Scholars (no. BK20170043).

Acknowledgments: N.Y. acknowledges the start-up funding support from ShanghaiTech University. The authors appreciate Analytical Instrumentation Center and chEM center of ShanghaiTech University.

Conflicts of Interest: The authors declare no conflict of interest.

\section{References}

1. Zhang, Y.; Knibbe, R.; Sunarso, J.; Zhong, Y.; Zhou, W.; Shao, Z.; Zhu, Z. Recent Progress on Advanced Materials for Solid-Oxide Fuel Cells Operating Below $500{ }^{\circ} \mathrm{C}$. Adv. Mater. 2017, 29, 1700132. [CrossRef] [PubMed]

2. Shao, Z.; Haile, S.M. A high-performance cathode for the next generation of solid-oxide fuel cells. Nature 2004, 431, 255-258. [CrossRef] [PubMed]

3. Kan, W.H.; Samson, A.J.; Thangadurai, V. Trends in electrode development for next generation solid oxide fuel cells. J. Mater. Chem. A 2016, 4, 17913-17932. [CrossRef] 
4. Gao, Z.; Mogni, L.V.; Miller, E.C.; Railsback, J.G.; Barnett, S.A. A perspective on low-temperature solid oxide fuel cells. Energ. Environ. Sci. 2016, 9, 1602-1644. [CrossRef]

5. Burnwal, S.K.; Bharadwaj, S.; Kistaiah, P. Review on MIEC Cathode Materials for Solid Oxide Fuel Cells. J. Mol. Eng. Mater. 2016, 4, 1630001. [CrossRef]

6. Nagai, T.; Ito, W.; Sakon, T. Relationship between cation substitution and stability of perovskite structure in $\mathrm{SrCoO}_{3-\delta}$-based mixed conductors. Solid State Ionics. 2007, 177, 3433-3444. [CrossRef]

7. Tahini, H.A.; Tan, X.; Zhou, W.; Zhu, Z.; Schwingenschlögl, U.; Smith, S.C. Sc and Nb dopants in $\mathrm{SrCoO}_{3}$ modulate electronic and vacancy structures for improved water splitting and SOFC cathodes. Energ. Storage. Mater. 2017, 9, 229-234. [CrossRef]

8. Zhou, W.; Jin, W.; Zhu, Z.; Shao, Z. Structural, electrical and electrochemical characterizations of $\mathrm{SrNb}_{0.1} \mathrm{Co}_{0.9} \mathrm{O}_{3-\delta}$ as a cathode of solid oxide fuel cells operating below $600{ }^{\circ} \mathrm{C}$. Int. J. Hydrogen Energy 2010, 35, 1356-1366. [CrossRef]

9. Zhou, W.; Shao, Z.; Ran, R.; Cai, R. Novel $\mathrm{SrSc}_{0.2} \mathrm{Co}_{0.8} \mathrm{O}_{3-\delta}$ as a cathode material for low temperature solid-oxide fuel cell. Electrochem. Commun. 2008, 10, 1647-1651. [CrossRef]

10. Chen, D.; Chen, C.; Gao, Y.; Zhang, Z.; Shao, Z.; Ciucci, F. Evaluation of pulsed laser deposited $\mathrm{SrNb}_{0.1} \mathrm{Co}_{0.9} \mathrm{O}_{3-\delta}$ thin films as promising cathodes for intermediate-temperature solid oxide fuel cells. J. Power. Sources. 2015, 295, 117-124. [CrossRef]

11. Zhu, Y.; Sunarso, J.; Zhou, W.; Jiang, S.; Shao, Z. High-performance $\mathrm{SrNb}_{0.1} \mathrm{Co}_{0.9-\mathrm{x}} \mathrm{Fe}_{\mathrm{x}} \mathrm{O}_{3-\delta}$ perovskite cathodes for low-temperature solid oxide fuel cells. J. Mater. Chem. A 2014, 2, 15454-15462. [CrossRef]

12. Zhou, C.; Zhang, Y.; Yang, G.; Gu, B.; Dai, J.; Zhang, J.; Zhou, W.; Shao, Z. Novel double perovskite with unique proton-oxygen ion-electron triple conducting species for low-temperature dual-ion ceramic fuel cells. Nanjing Tech University, Nanjing, China. Unpublished work. 2019.

13. Wang, S.; Jin, F.; Li, L.; Li, R.; Qu, B.; He, T. Stability, compatibility and performance improvement of $\mathrm{SrCo}_{0.8} \mathrm{Fe}_{0.1} \mathrm{Nb}_{0.1} \mathrm{O}_{3-\delta}$ perovskite as a cathode for intermediate-temperature solid oxide fuel cells. Int. J. Hydrogen. Energy 2017, 42, 4465-4477. [CrossRef]

14. Zhou, W.; Sunarso, J.; Zhao, M.; Liang, F.; Klande, T.; Feldhoff, A. A highly active perovskite electrode for the oxygen reduction reaction below $600^{\circ} \mathrm{C}$. Angew. Chem. Int. Edit. 2013, 52, 14036-14040. [CrossRef] [PubMed]

15. Zhu, Z.; Shi, Y.; Aruta, C.; Yang, N. Improving Electronic Conductivity and Oxygen Reduction Activity in Sr-Doped Lanthanum Cobaltite Thin Films: Cobalt Valence State and Electronic Band Structure Effects. ACS Appl. Energy Mater. 2018, 1, 5308-5317. [CrossRef]

16. Santiso, J.; Burriel, M. Deposition and characterisation of epitaxial oxide thin films for SOFCs. J. Solid. State. Electro. 2010, 15, 985-1006. [CrossRef]

17. Baumann, F.S.; Maier, J.; Fleig, J. The polarization resistance of mixed conducting SOFC cathodes: A comparative study using thin film model electrodes. Solid. State. Ionics. 2008, 179, 1198-1204. [CrossRef]

18. Yang, N.; D’Epifanio, A.; Di Bartolomeo, E.; Pugnalini, C.; Tebano, A.; Balestrino, G.; Licoccia, S. $\mathrm{La}_{0.8} \mathrm{Sr}_{0.2} \mathrm{Ga}_{0.8} \mathrm{Mg}_{0.2} \mathrm{O}_{3-\delta}$ thin films for IT-SOFCs: Microstructure and transport properties correlation. J. Power. Sources. 2013, 222, 10-14. [CrossRef]

19. Mori, D.; Oka, H.; Suzuki, Y.; Sonoyama, N.; Yamada, A.; Kanno, R.; Sumiya, Y.; Imanishi, N.; Takeda, Y. Synthesis, structure, and electrochemical properties of epitaxial perovskite $\mathrm{La}_{0.8} \mathrm{Sr}_{0.2} \mathrm{CoO}_{3}$ film on YSZ substrate. Solid. State. Ionics. 2006, 177, 535-540. [CrossRef]

20. Aruta, C.; Tebano, A. Thin Films and Superlattice Synthesis; Wiley-VCH Verlag GmbH \& Co. KGaA: Weinheim, Germany, 2015.

21. Vu, H.T.; Nguyen, M.D.; Houwman, E.; Boota, M.; Dekkers, M.; Vu, H.N.; Rijnders, G. Ferroelectric and piezoelectric responses of (110) and (001)-oriented epitaxial $\mathrm{Pb}\left(\mathrm{Zr}_{0.52} \mathrm{Ti}_{0.48}\right) \mathrm{O}_{3}$ thin films on all-oxide layers buffered silicon. Mater. Res. Bull. 2015, 72, 160-167. [CrossRef]

22. Chen, G.; Wang, Y.; Sunarso, J.; Liang, F.; Wang, H. A new scandium and niobium co-doped cobalt-free perovskite cathode for intermediate-temperature solid oxide fuel cells. Energy. 2016, 95, 137-143. [CrossRef]

23. Wang, Z.; Huang, X.; Lv, Z.; Zhang, Y.; Wei, B.; Zhu, X.; Wang, Z.; Liu, Z. Preparation and performance of solid oxide fuel cells with YSZ/SDC bilayer electrolyte. Ceram. Int. 2015, 41, 4410-4415. [CrossRef]

24. Wu, M.-H.; Huang, J.-L.; Fung, K.-Z.; Liu, H.-C.; Lii, D.-F. Nanostructure and conductivity study of yttria doped zirconia films deposited on samaria doped ceria. Appl. Surf. Sci. 2011, 257, 7871-7875. [CrossRef]

25. Tuller, H. Ionic Conduction and Applications. In Springer Handbook of Electronic and Photonic Materials, 2nd ed.; Kasap, S., Capper, P., Eds.; Springer: Berlin, Germany, 2017; p. 1. 
26. Crumlin, E.J.; Mutoro, E.; Ahn, S.-J.; la O', G.J.; Leonard, D.N.; Borisevich, A.; Biegalski, M.D.; Christen, H.M.; Shao-Horn, Y. Oxygen Reduction Kinetics Enhancement on a Heterostructured Oxide Surface for Solid Oxide Fuel Cells. J. Phys. Chem. Lett. 2010, 1, 3149-3155. [CrossRef]

27. Van der Heide, P.A.W. Systematic x-ray photoelectron spectroscopic study of $\mathrm{La}_{1-\mathrm{x}} \mathrm{Sr}_{\mathrm{x}}$-based perovskite-type oxides. Surf. Interface. Anal. 2002, 33, 414-425. [CrossRef]

28. Mutoro, E.; Crumlin, E.J.; Biegalski, M.D.; Christen, H.M.; Shao-Horn, Y. Enhanced oxygen reduction activity on surface-decorated perovskite thin films for solid oxide fuel cells. Energ. Environ. Sci. 2011, 4, 3689. [CrossRef]

29. Kochubey, D.; Kaichev, V.; Saraev, A.; Tomyn, S.; Belov, A.; Voloshin, Y. Combined X-ray Absorption Near-Edge Structure and X-ray Photoelectron Study of the Electrocatalytically Active Cobalt(I) Cage Complexes and the Clathrochelate Cobalt(II)- and Cobalt(III)-Containing Precursors and Analogs. J. Phys. Chem. C 2013, 117, 2753-2759. [CrossRef]

30. Cai, Z.; Kubicek, M.; Fleig, J.; Yildiz, B. Chemical Heterogeneities on $\mathrm{La}_{0.6} \mathrm{Sr}_{0.4} \mathrm{CoO}_{3-\delta}$ Thin FilmsCorrelations to Cathode Surface Activity and Stability. Chem. Mater. 2012, 24, 1116-1127. [CrossRef]

31. Orikasa, Y.; Crumlin, E.J.; Sako, S.; Amezawa, K.; Uruga, T.; Biegalski, M.D.; Christen, H.M.; Uchimoto, Y.; Shao, H.Y. Surface strontium segregation of solid oxide fuel cell cathodes proved by in situ depth-resolved X-ray absorption spectroscopy. ECS Electrochem. Lett. 2014, 3, F23-F26. [CrossRef]

(c) 2019 by the authors. Licensee MDPI, Basel, Switzerland. This article is an open access article distributed under the terms and conditions of the Creative Commons Attribution (CC BY) license (http://creativecommons.org/licenses/by/4.0/). 